\title{
ESL Teachers' Attitudes and Competence on Communicative Language Teaching (CLT) Methodology
}

\author{
Rogelio A. Banagbanag \\ Department of Languages and Communication, College of Arts and Communication, University of Eastern Philippines, \\ Catarman, Northern Samar, 6400, Philippines
}

Received March 18, 2020; Revised May 1, 2020; Accepted May 20, 2020

Copyright $(2020$ by authors, all rights reserved. Authors agree that this article remains permanently open access under the terms of the Creative Commons Attribution License 4.0 International License

\begin{abstract}
The English teaching curriculum imposed by the Department of Education in the Philippines is based on the Communicative Language Teaching (CLT) methodology. However, the traditional method of teaching such as Grammar-Translation still dominates in ESL practices in the country. This study determined the profile of ESL teachers, their attitude towards CLT, their teaching competence and the difficulties they experienced in using CLT in the classroom. The descriptive-correlational research design aided by an actual classroom observation was used in this study. A questionnaire and the classroom observations served as the instruments for collecting data. There were 178 ESL teachers and 73 secondary school heads who served as respondents of the study. Results revealed that a majority of the teachers were holders of a bachelor's degree; taught English subject for more or less four (4) years; finished college degree course in public schools; and had less trainings attended. It also revealed that a majority of the teachers had positive attitude toward CLT. As regards their teaching competence, they were rated "most competent" in their language skills while "more competent" in their teaching skills, classroom management, and evaluation skills. On the difficulties they experienced in using CLT in their classes, they considered the following challenges as "more difficult": fewer opportunities to get CLT training; low level of students' English proficiency; the big number of students in a class; and the lack of efficient and effective instruments to assess communicative competence.
\end{abstract}

Keywords Attitudes, CLT, Competence, ESL, Teaching

\section{Introduction}

One of the programs of the Department of Education in the Philippines that helps promote functional literacy in language teaching articulates the use of Communicative Language Teaching (CLT). This methodology, which originated in England in the 1960s, is widely used in English as Second Language (ESL) classrooms around the world[1] including the Philippines. Signifying the new and being endorsed as a reaction against the traditional language teaching methodologies, CLT has served as a major source of influence on English teaching in ESL environments.

According to Richards and Rogers[2], Communicative Language Teaching is a teaching methodology that focuses on real communication vis-à-vis language learning that provides the opportunity to experiment, high tolerance on errors in order to build communicative competence, and opportunity to develop accuracy and fluency. It helps develop students' abilities to use English appropriately in context.[3] Richard and Rogers[4] point out that CLT emphasizes the process of communication and leads learners to different roles. The learners act as a negotiator between the self, the learning process, and the object of learning where they actively engage in negotiating meaning by trying to make them understood and to understand others in the classroom activities. In using CLT, both accuracy and fluency should be taken into consideration in language teaching, but the aim is to build fluency.[5]

Communicative Language Teaching highlights a radical change of the traditional structured teaching methods which have lived through history. Contrary to the teacher-centered approach, where teachers are regarded as knowledge givers and learners are receivers, CLT reflects a more social relationship between the teacher and learner [6].

Although the current English teaching curriculum imposed by the Department of Education is clearly based on the communicative language teaching methodology, 
and a student-centered approach has been officially adopted, traditional method such as the Grammar-Translation still dominates in ESL practices in the country, particularly in schools in the province of Northern Samar, Philippines.

The reason for this mismatch between communicative language teaching theory and practice may be teachers' attitudes.[7] It is clear that teachers' attitudes are important in their decision to implement communicative language teaching. Since teachers' attitudes reveal their thinking about teaching language, the investigation of teachers' attitudes and the perceived difficulties serves as a starting point to identify the possible contradictions between teachers' beliefs and communicative language teaching principles. Littlewood[8] suggests that the idea of the communicative approach may conflict with ESL teachers' existing thought about teachers' roles and teaching methods.

Karavas-Doukas[9] affirms that the attitudes of the teachers are important in their decision to implement communicative language teaching. Their attitudes and beliefs shape the sense they make of any educational innovation, and play a critical role in how they behave in the classroom situation. Teachers' attitudes play a crucial role in revealing teachers' thinking about communicative language teaching and its implementation in the classroom. Teachers' favorable beliefs and attitudes toward the methodology are important factors that make them adopt it in their classrooms successfully. Thus, to implement the methodology, it is important to investigate ESL teachers' attitudes and perceived difficulties towards communicative language teaching.

\section{Objectives}

This study determined the ESL teachers' attitudes and competence on Communicative Language Teaching (CLT) methodology. Specifically this study (1) described the profile of the teachers; (2) determined their attitude towards communicative language teaching; (3) assessed the extent of their teaching competencies; (4) looked into the difficulties of the ESL teachers towards communicative language teaching; (5) found out significant relationships between the teachers' profile, their attitude towards communicative language teaching and their teaching competence, and between their teaching competence and their attitude towards communicative language teaching.

\section{Methodology}

This study used the descriptive-correlational research design that covered selected secondary school ESL teachers in the province of Northern Samar, Philippines. A total of 178 teachers were taken as respondents coming from public secondary schools in the province. Moreover, 73 school heads also participated in the survey specifically in assessing the teaching competence of the teacher-respondents.

The study used the instrument developed by Karavas-Doukas[10] on teachers' attitudes towards the principles of Communicative Language Teaching, while the instrument on teaching competence was adopted from the study of Amor[11]. The survey questionnaire on the perceived difficulties in the implementation of Communicative Language Teaching was adopted from Ozsevik[12].

Frequency distribution and percentages were used in presenting the profile of the teacher-respondents. In determining the attitudes and the perceived difficulties in the use of Communicative Language Teaching, the weighted mean was used. In the tests of relationship, multiple regression analysis was used.

In scoring and interpreting the data, the following scales were used:

On teaching competence: 4.20-5.00 most competent; 3.40-4.19 more competent; 2.60-3.39 competent; 1.80-2.59 less competent; and 1.00-1.79 not competent.

On the level of attitude towards CLT: 4.20-5.00 highly positive; $3.40-4.19$ positive; $2.60-3.39$ moderately positive; $1.80-2.59$ slightly positive; and 1.00-1.79 negative.

On the level of difficulty: $4.20-5.00$ most difficult; 3.40-4.19 more difficult; $2.60-3.39$ difficult; $1.80-2.59$ less difficult; and 1.00-1.79 not difficult.

\section{Results and Discussion}

\subsection{Profile of the Respondents}

Among the 178 teacher-respondents, a majority of them, with a total of 112 or $63 \%$ were graduates of a bachelor's degree, 46 or 25.8 had earned units towards a master's degree, 10 or $5.6 \%$ had earned a master's degree, 5 or $2.8 \%$ had earned units towards a doctorate degree and another 5 or $2.8 \%$ had earned a doctorate degree.

As regards their experience in teaching the English language, a majority of them with a total of 102 or $57.3 \%$ had been teaching for a maximum of four (4) years, 38 or $21.4 \%$ had an experience of teaching English for 5-9 years, 12 or 6.7 had $10-14$ years, 13 or $7.3 \%$ each for those with an experience of 15-19 years and 20 years and above.

A majority of the respondents were graduates of public universities in the country with a frequency of 171 or $96 \%$, only seven (7) or $4 \%$ were graduates of private schools in the country.

As regards the number of trainings and seminars that they have attended, most of them, with a frequency of 90 or $50.5 \%$, had not attended a single training regarding CLT. While there were 33 or $18.5 \%$ had attended at least one (1) relevant training, 26 or 14.6 had attended two (2) 
relevant training, 17 or 9.6 had three (3) trainings, six (6) or $3.4 \%$ had attended 4 trainings and another six (6) or $3.4 \%$ had attended five (5) and above number of trainings and seminar relevant to CLT.

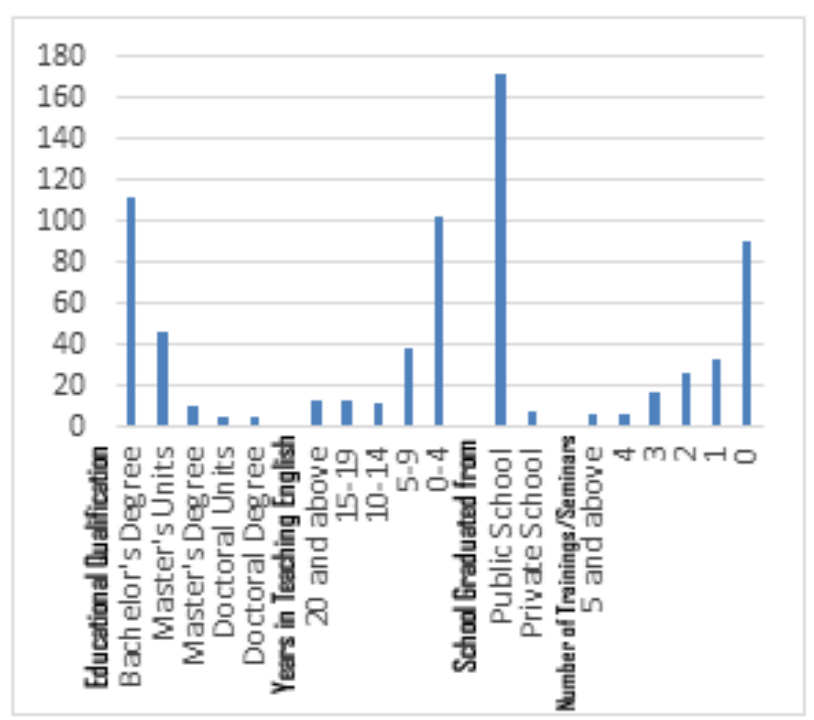

Figure 1. Profile of the Respondents

\subsection{Attitudes of ESL Teachers towards Communicative Language Teaching}

There were 41 items in the instrument on attitudes towards CLT adopted from Karavas-Doukas[13], and from these, teachers showed "highly positive" attitude on 23 items. Among these items, teachers of English believed that classroom activities should be meaningful and value real communication. This indicator showed the highest mean of 4.87. The indicator that says that "people learn a language through communicating it" had a mean of 4.78. These indicators received a "highly positive" attitude from teachers, which explain that the teaching of English will be more effective when it is used in a real-life context where students can use the language appropriately in different form of discourses.

On the other hand, the teachers had a slightly positive attitude, with a mean of 1.81 , on students mastering the rules of grammar to make them capable of communicating with a native speaker of the language. This indicates that teachers did not rely on the knowledge of grammar as the primary vehicle to develop communicatively competent learners.

Overall, the study showed that teachers of English in the secondary schools surveyed had a "positive" attitude towards CLT with a grand mean of 3.89. Teachers had favorable attitudes towards the use of CLT in the language classroom as a potential approach in nurturing learners' communicative competence. Teachers who held positive attitudes towards CLT tended to use communicative activities in their classroom practice.

Actual classroom observation and interview among secondary school teachers of English revealed the reasons behind their favorable or positive attitude towards CLT, and this can be summarized as follows:

Communicative Language Teaching pays attention to both form and function. Based on observation, the teachers support CLT because it is helpful in developing the students' communicative competence as well as linguistic knowledge as some of them used the activities suggested for CLT classes. The teachers' beliefs revealed that their teaching goal is to develop the students' communicative competence because it is observed that they encouraged their learners to use the language in meaningful context. Nevertheless, they did not exclude teaching grammar. Based on observation, both linguistic form and communicative functions are important in learning a language. For the teacher-respondents, knowledge of the grammar of the language serves as foundation for one to effectively use the language in communication. The teachers' perception and their way of teaching in English echo a number of researchers' claims that there is value in communicative approach which involves grammar teaching.[14]

Communicative Language Teaching develops language abilities through use. The findings of the study indicate that teachers of English were in favor or had positive attitudes towards CLT because the activities given in the English classes focused on the development of the students' abilities to use the target language. The teachers believed that it is essential to expose the students to the target language in order to acquire conversation in a life-like situation. To accomplish this goal, group or pair work activities were designed to promote communication in the classrooms. Communicative activities made use of authentic situations where communication takes place naturally because some teachers used magazines, movies and other authentic materials.

Communicative Language Teaching takes into account the affective variables in language learning. Although the secondary school teachers of English perceived CLT to be effective in developing the students' language skills, the teachers considered the affective as well as the cognitive aspects of second language learning as reflected in their activities involving appreciation of literature. The findings in the study confirmed that the teachers preferred CLT compared to the traditional teaching methods because CLT creates a safe and engaged learning environment especially when they are giving group activities. More specially, CLT not only enhances the learners' English proficiency, but creates a classroom atmosphere that encourages risk-taking and cooperative relationship in group because students become participative in the class.

Communicative Language Teaching develops learner autonomy in the learning process. Drawn from the findings of the study, the teachers believed that CLT could help develop learner autonomy because of the activities given to the class that tended learners to work responsively and cooperatively. The teachers of English in 
this study addressed the importance of learner autonomy in the language learning process. CLT enables learners become autonomous when they take charge of their own learning.

\subsection{Teaching Competence of ESL Teachers}

The teaching competence of ESL teachers in secondary schools was evaluated by their school heads. They were evaluated in the following competencies: language skills, teaching skills, classroom management, and evaluation skills.

As regards their language skills, ESL teachers in secondary schools were "most competent" in using English, with a weighted mean of 4.21. It was found out that teachers of English observed correct spelling and spelling rules consistently. It had the highest mean of 4.38, which means that teachers were most competent in this aspect. This means that ESL teachers are competent enough in analyzing the structure of words as used in the language context. The lowest mean, 4.08, was on the indicator that ESL teachers skillfully integrate the lessons in English with relevant topics. This is interpreted as "more competent". It means that the teachers of English possess the ability to contextualize the teaching of the English subject in the other field.

ESL teachers were "more competent" in their teaching skills. This means that they are already skilled in delivering the lessons guided by the principles of teaching. Specifically, teachers interact with the students fluently in English. This had the mean of 4.30, interpreted as "most competent". This means that the ESL teachers can use the target language spontaneously in instructing various communicative activities in the English classes. The indicator which stimulates thinking and clarifies lessons through giving questions on Higher Order Thinking Skills (HOTS) was considered the lowest with a weighted mean of 4.10, interpreted as "more competent". This indicates that ESL teachers had already inculcated and practiced in their language classes the art of questioning.

When it comes to the classroom management, the highest mean is 4.37 which states that English teachers were "most competent" in commanding respect from the students. This implies that the English teachers are well-oriented in maintaining the order and discipline in the classroom. On the other hand, the lowest mean, 3.97, interpreted as "more competent", indicates the teachers' ability to prepare adequate learning activities for the daily lessons in English. This means that the teachers of English had sufficient activities facilitated in the English class to reinforce learning. Generally, the English teachers were "more competent" as indicated in its weighted mean of 4.10. It means that the teachers of English were efficient classroom managers in facilitating the lessons.

Regarding their evaluation skills, the highest weighted mean falls on the indicator which states that the teachers of English treat each student fairly and squarely. The mean is 4.35 which is interpreted as "most competent". This means that the teachers of English were objective in evaluating the performance of the learners. In contrast, the lowest mean which is interpreted as "more competent" is 3.37 which refers to selecting and utilizing criterion-referenced tests. This infers that the teachers of English evaluate the performance of the learners based on their set of standard. The evaluation skills of the teachers in general had a grand weighted mean of 4.13 which means "more competent". This explains that they adhere to the standard principles of measurement and evaluation.

Table 1. Teaching Competence of ESL Teachers

\begin{tabular}{|c|c|c|}
\hline Competencies & Mean & Interpretation \\
\hline Language Skills & 4.21 & Most Competent \\
\hline Teaching Skills & 4.19 & More Competent \\
\hline Classroom Management & 4.10 & More Competent \\
\hline Evaluation Skills & 4.13 & More Competent \\
\hline
\end{tabular}

\subsection{Difficulties Experienced by ESL Teachers in using Communicative Language Teaching}

The difficulties of ESL teachers towards using Communicative Language Teaching are categorized into: teacher-related difficulties and challenges; student-related difficulties and challenges; difficulties and challenges related to educational system; and CLT-related difficulties and challenges[15].

\subsubsection{Teacher-related Difficulties}

Based on the result of the computation it is observed that the highest mean is 3.88 which means that the teachers of English encountered more difficulties on the opportunities of the teachers to get CLT training. This indicates that the teachers of English tended to have difficulties in adopting CLT because they lack the training called for to enhance their understanding and mastery on the use of CLT. On the other side, the lowest mean is 3.19 which is interpreted as "difficult" when it comes to the teachers' knowledge about the appropriate use of language in context. This means that the teachers experienced difficulty to use the language in various forms of discourses or in varied situations. In general, the teachers' difficulties in CLT are characterized as "more difficult" as indicated in the grand mean of 3.50. This means that the teachers of English were not well-oriented on CLT and their difficulties on spoken language hindered their efficacy in language instruction.

\subsubsection{Student-related Difficulties}

On student-related difficulties and challenges, the frequency distribution and its weighted mean, came out that the highest mean is 3.97 which means "more difficult" on the students' low-level English proficiency. 
This explains that the students' communicative competence is considered major constraint in the difficulties encountered in using CLT. On the other hand, the lowest mean is 3.60 that is also considered "more difficult" when the students had passive style of learning. This indicates that the CLT cannot be utilized effectively in the English class because they lack the motivation towards language learning. In general, the student-related difficulties are interpreted as "more difficult" due to its grand mean of 3.78 which indicates that the students' communication skills and their interest towards the English subjects affected in the implementation of the communicative activities in CLT.

\subsubsection{Educational System-related Difficulties}

On the difficulties and challenges related to the educational system, it was found out that the highest mean is 3.81 which is "more difficult" for the teachers of English to effectively hold classes in a big class using CLT. This means that an overcrowded class is not ideal for CLT activities. While the lowest mean, 3.13, interpreted as "difficult", states that grammar-based examinations have a negative impact on the use of CLT. This infers that the teachers of English experience difficulties in reconciling between the grammar-based examinations and the activities proposed in the language classroom using CLT.

The grand mean of 3.64 indicates that the difficulties and challenges related to educational system are considered "more difficult". It tells that the management of institution where the language instruction operates influences the difficulties of the ESL teachers in CLT.

\subsubsection{CLT-related Difficulties}

On the CLT-related difficulties and challenges, the highest mean is 3.9 which is interpreted as "more difficult". This indicates that there is lack of effective and efficient instruments to assess communicative competence. This means that teachers of English tend to have difficulties in CLT due to the limitation of coming up with an appropriate evaluation tool that would measure the performance of the students in English. In contrast, the lowest mean is 3.30 which falls under the "difficult" level. It signifies that CLT does not take into account the differences between EFL and ESL teaching contexts. This implies that the unique features for ESL teaching do not match with the EFL teaching which resulted in the difficulties of the ESL teachers to use CLT appropriately in the context.

The grand mean of 3.64 signifies "more difficult" for the ESL teachers to use CLT due to some limitations of the approach in language teaching as well its weakness in ESL teaching.

These findings on the difficulties of the ESL teachers toward CLT seemed inconsistent to the level of teaching competence of the teachers of English because the ratings of the teachers were based on the perception of the school heads.

Based on actual observation, the following were considered major constraints why the teachers encountered difficulties in adopting communicative language teaching in English.

On teacher-related difficulties, it was observed that teachers were dependent on the use of textbooks rather than using authentic materials because these things were not readily available; teachers had heavy workload; teachers were not well-oriented on how to utilize CLT in the class because they have limited knowledge on the communicative activities proposed in the CLT.

Regarding student-related difficulties, students were not proficient enough in the English language. They would usually switch to their mother tongue, or else they hesitated to participate in communicative activities and most students were passive learners.

The difficulties related to the educational system were: copies of the modules provided by the Department of Education were not enough for the students; some of these modules were not regularly updated; some classrooms were not conducive for learning; classrooms were too crowded; the administration lacked support for the full implementation of CLT.

Assessment tool that is suited for CLT was not also sufficient.

Table 2. Difficulties in Using CLT

\begin{tabular}{|c|c|c|}
\hline Difficulties & Mean & Interpretation \\
\hline Teacher-related & & \\
\hline Proficiency in spoken English & 3.80 & More Difficult \\
\hline $\begin{array}{c}\text { Appropriate use of language in } \\
\text { context }\end{array}$ & 3.19 & Difficult \\
\hline $\begin{array}{c}\text { Knowledge about the culture of } \\
\text { the target language }\end{array}$ & 3.25 & Difficult \\
\hline Opportunities to get CLT training & 3.88 & More Difficult \\
\hline Materials development & 3.45 & More Difficult \\
\hline Misconceptions about CLT & 3.44 & More Difficult \\
\hline Student-related & 3.97 & More Difficult \\
\hline English proficiency & 3.60 & More Difficult \\
\hline Style of learning & 3.84 & More Difficult \\
\hline $\begin{array}{c}\text { Participation in communicative } \\
\text { class activities }\end{array}$ & 3.70 & More Difficult \\
\hline $\begin{array}{c}\text { Motivation for developing } \\
\text { communicative competence }\end{array}$ & 3.87 & More Difficult \\
\hline Educational-related & 3.30 & Difficult \\
\hline Administrative support & 3.42 & More Difficult \\
\hline Availability of authentic materials & 3.74 & More Difficult \\
\hline $\begin{array}{c}\text { View on teachers' and learners' } \\
\text { role on CLT }\end{array}$ & 3.53 & More Difficult \\
\hline Class size & 3.81 & More Difficult \\
\hline Grammar-based examination & 3.13 & Difficult \\
\hline CLT-related & & \\
\hline efficient assessment instruments & 3.87 Difficult \\
\hline Cultural contexts & 3.76 & More \\
\hline
\end{tabular}




\subsection{Tests of Relationship}

On the test of relationship between profile of the respondents and their teaching competence, findings revealed that educational qualification, and the school where the respondents graduated from, were significantly related to their teaching competence while the number of years in teaching, and the trainings and seminars attended, were not significant. It shows that appropriate educational preparation and the school where they earned their degrees help the teachers become more competent in their teaching. However, the length of service as teachers of English does not guarantee that they will perform well in the teaching of English, much in the use of CLT. The trainings attended by ESL teachers were not determinant factors to enhance their teaching competence. This means that the things learned in trainings were not applied in the actual classroom teaching.

Regarding the relationship between the profile of the respondents and their attitude towards CLT, it was revealed that educational qualification, school graduated from, and trainings attended were significantly related to their attitudes towards communicative language teaching in English while the number of years in teaching was not significant. The result shows that the educational qualification of the teachers, the school where they graduated from, and the trainings they have attended bear so much in developing positive attitude towards CLT.
Between the profile of the respondents and their perceived difficulties in CLT, it was revealed that educational qualification, number of years in teaching, and trainings attended were significantly related to the difficulties in communicative language teaching in English while the school graduated from was not significant. This explains that the teachers' educational preparation, number of years of teaching the subject, trainings and seminars attended related to English teaching particularly on CLT, are crucial for them to overcome the difficulties they have encountered.

The test of relationship between the teaching competence of the ESL teachers and their attitudes towards CLT revealed that the teaching competence was found to be significantly related to the attitudes of the teachers towards communicative language teaching in English. This shows that the attitudes of teachers towards CLT have no bearing in their teaching competence.

On the relationship between teaching competence of the ESL teachers and their difficulties in CLT, it was revealed that the teaching competence of the ESL teachers was found not significantly related to the difficulties in communicative language teaching English. This means that regardless of the difficulties experienced by the teachers in adopting CLT in their classrooms, their teaching competence does not have a great influence in the use of the activities proposed in CLT.

Table 3. Tests of Relationships

\begin{tabular}{|c|c|c|c|c|}
\hline Tests & f-ratio & Significant $\mathbf{f}$ & $\begin{array}{c}\text { Coefficient of } \\
\text { Determination } \\
\left(r^{2} \times 100 \%\right) \\
\end{array}$ & Interpretation \\
\hline \multicolumn{5}{|l|}{ Profile and Teaching Competence } \\
\hline Educational Qualification & .85456 & .356529 & .48 & Significant \\
\hline Years in Teaching & .32307 & .57049 & .18 & Not Significant \\
\hline School Graduated from & .99277 & .320434 & .56 & Significant \\
\hline Trainings Attended & .15956 & .690043 & .09 & Not Significant \\
\hline \multicolumn{5}{|l|}{ Profile and Attitude towards CLT } \\
\hline Educational Qualification & 4.44108 & .036501 & 2.46 & Significant \\
\hline Years in Teaching & .111992 & .738286 & .06 & Not Significant \\
\hline School Graduated from & 7.94404 & .005377 & 4.13 & Significant \\
\hline Trainings Attended & 5.27152 & .022856 & 2.90 & Significant \\
\hline \multicolumn{5}{|l|}{ Profile and Difficulties in using CLT } \\
\hline Educational Qualification & 6.22683 & .013504 & 3.41 & Significant \\
\hline Years in Teaching & 1.69595 & .19452 & .95 & Significant \\
\hline School Graduated from & 0.18286 & .669449 & .10 & Not Significant \\
\hline Trainings Attended & 1.32040 & .252079 & .74 & Not Significant \\
\hline $\begin{array}{c}\text { Teaching Competence and Attitude } \\
\text { towards CLT }\end{array}$ & 0.42275 & .516414 & .24 & Not Significant \\
\hline $\begin{array}{l}\text { Teaching Competence and Difficulties } \\
\text { in using CLT }\end{array}$ & 0.03808 & .8455 & .02 & Not Significant \\
\hline
\end{tabular}




\section{Conclusions}

Communicative Language Teaching creates a non-threatening language environment that lowers the learners' anxiety and makes class input comprehensible. When CLT is used in the classroom, students can develop their language as well as social skills when they work together with their group members to achieve a common goal.

The teachers hold a favorable attitude towards CLT and display characteristics of CLT in their beliefs. CLT assists the students to comprehend linguistic forms and use these rules for communication. From the perspective of the teachers, communicative activities are helpful for the students to practice rules in meaningful contexts.

Most of the teachers of English are "most competent" in the language skills while "more competent" in the teaching skills, classroom management, and evaluation skills. This implies that the teachers have sufficient linguistic competence needed in the teaching of English.

The teaching competence of the teachers of English is not relevant to establish positive attitude towards CLT in English. This means that the teaching competence of the teachers of English is not a determinant factor to develop positive attitude towards CLT. This also means that teachers can develop positive attitude towards CLT even if they are not totally competent.

\section{Acknowledgments}

The researcher is thankful to the secondary ESL teachers of Northern Samar for their support and their participation in the survey.

\section{REFERENCES}

[1] S. Thamarana. "A Critical Overview of Communicative Language Teaching". 5th International Conference on English Language and Literature (ICELL - 2014). Hyderabad, India. June 28 - 29, 2014.

[2] J. C. Richards and T. Rogers. Approaches and Methods in Language Teaching. Second Edition. New York: Cambridge University Press. 2006.

[3] D. Larsen-Freeman. Techniques and Principles in Language Teaching. $2^{\text {nd }}$ Edition. Oxford, New York: Oxford University Press. 2000.
[4] J. C. Richards and T. Rogers. Approaches and Methods in Language Teaching. Second Edition. New York: Cambridge University Press. 2006.

[5] D. H. Brown. Principles of Language Learning and Teaching. $5^{\text {th }}$ edition. New York: Pearson Education, Inc. 2006.

[6] M. Chang. "Factors Affecting the Implementation of Communicative Language Teaching in Taiwanese College English Classes". English Language Teaching, vol. 4, no. 2. June 2011.

[7] E. Karavas-Doukas. (1995). “Teacher Identified Factors Affecting the Implementation of an EFL Innovation in Greek Public Secondary Schools." Language, Culture and Curriculum, 8:1, 53-68, DOI: 10.1080/0790831950952518 8.

[8] W. Littlewood. "Communicative and Task-based Language Teaching in East Asian Classrooms. Language Teaching, vol. 40. 2007, $243-249$.

[9] E. Karavas-Doukas. (1995). "Teacher Identified Factors Affecting the Implementation of an EFL Innovation in Greek Public Secondary Schools." Language, Culture and Curriculum, 8:1, 53-68, DOI: 10.1080/0790831950952518 8

[10] E. Karavas-Doukas. (1995). “Teacher Identified Factors Affecting the Implementation of an EFL Innovation in Greek Public Secondary Schools." Language, Culture and Curriculum, 8:1, 53-68, DOI: 10.1080/0790831950952518 8

[11] M. A. T. Amor. "The Current Conditions in the Teaching of English in the Secondary Schools of Balicuatro Area, Province of Northern Samar". (Unpublished Master's Thesis, University of Eastern Philippines. 2011.

[12] Z. Ozsevik. "The Use of Communicative Language Teaching (CLT): Turkish EFL Teachers' Perceived Difficulties in Implementing CLT in Turkey." Master of Arts in Teaching of English as a Second Language, Urbana, University of Illinois, 2010.

[13] E. Karavas-Doukas. (1995). "Teacher Identified Factors Affecting the Implementation of an EFL Innovation in Greek Public Secondary Schools." Language, Culture and Curriculum, 8:1, 53-68, DOI: 10.1080/0790831950952518 8.

[14] G. Thompson. "Some Misconceptions about Communicative Language Teaching”. ELT Journal, vol. 50, no. $1,1996$.

[15] Z. Ozsevik. "The Use of Communicative Language Teaching (CLT): Turkish EFL Teachers' Perceived Difficulties in Implementing CLT in Turkey." Master of Arts in Teaching of English as a Second Language, Urbana, University of Illinois, 2010. 